\title{
Case Report \\ Two Cases of Lacaziosis in Bottlenose Dolphins (Tursiops truncatus) in Japan
}

\author{
Keiichi Ueda, ${ }^{1}$ Ayako Sano, ${ }^{2}$ Jyoji Yamate, ${ }^{3}$ Eiko Itano Nakagawa, ${ }^{4}$ Mitsuru Kuwamura, ${ }^{3}$ \\ Takeshi Izawa, ${ }^{3}$ Miyuu Tanaka, ${ }^{3}$ Yuko Hasegawa, ${ }^{3}$ Hiroji Chibana, ${ }^{5}$ Yasuharu Izumisawa, ${ }^{6}$ \\ Hirokazu Miyahara, ${ }^{1}$ and Senzo Uchida ${ }^{1}$ \\ ${ }^{1}$ General Research Center, Okinawa Churaumi Aquarium, Aza Ishikawa 888, Motobu-Cho, Kunigami-Gun, \\ Okinawa 905-0206, Japan \\ ${ }^{2}$ Department of Animal Sciences, Faculty of Agriculture, University of the Ryukyus, Sembaru 1, Nishihara-Cho, Nakagusuku-Gun, \\ Okinawa 903-0213, Japan \\ ${ }^{3}$ Laboratory of Veterinary Pathology, Division of Veterinary Sciences, Rinku-Campus, Osaka Prefecture University, \\ Rinku Ohrai Kita 1-58, Izumisano, Osaka 598-8531, Japan \\ ${ }^{4}$ Department of Pathological Science, CCB, State University of Londrina, P.O. Box 6001, 86051-970 Londrina, PR, Brazil \\ ${ }^{5}$ Medical Mycology Research Center, Chiba University, Inohana 1-8-1, Chiba 260-8673, Japan \\ ${ }^{6}$ Department of Veterinary Medicine, Rakuno Gakuen University, Bunkyodai Midorimachi 582, Ebetu, \\ Hokkaido 069-0836, Japan
}

Correspondence should be addressed to Ayako Sano; aya_grimalkin@yahoo.co.jp

Received 21 June 2013; Accepted 4 August 2013

Academic Editors: J. Lakritz, F. Mutinelli, R. L. Santos, and S. Stuen

Copyright (C) 2013 Keiichi Ueda et al. This is an open access article distributed under the Creative Commons Attribution License, which permits unrestricted use, distribution, and reproduction in any medium, provided the original work is properly cited.

Lacaziosis, formerly called lobomycosis, caused by Lacazia loboi, is a zoonotic mycosis found in humans and dolphins and is endemic in the countries on the Atlantic Ocean. Although the Japanese coast is not considered an endemic area, photographic records of lacaziosis-like skin lesions were found in bottlenose dolphins (Tursiops truncatus) that were migrating in the Goto Islands (Nagasaki Prefecture, Japan). We diagnosed 2 cases of lacaziosis in bottlenose dolphins captured simultaneously at the same coast within Japanese territory on the basis of clinical characteristics, cytology, histopathology, immunological tests, and detection of partial sequences of a $43 \mathrm{kDa}$ glycoprotein coding gene $(\mathrm{gp} 43)$ with a nested-PCR system. The granulomatous skin lesions from the present cases were similar to those found in animals from endemic areas, containing multiple budding and chains of round yeast cells and positive in the immune-staining with anti-Paracoccidioides brasiliensis serum which is a fungal species related to L. loboi; however, the gp43 gene sequences derived from the present cases showed $94.1 \%$ homology to P. brasiliensis and $84.1 \%$ to L. loboi. We confirmed that the causative agent at the present cases was different genotype of $L$. loboi from Amazon area.

\section{Introduction}

Lacaziosis is a granulomatous chronic skin infection caused by the fungus Lacazia loboi and is endemic in the Atlantic coastal waters of Latin American countries [1-3]. Interestingly, $L$. loboi is a sister taxon with a close phylogenetic relationship to Paracoccidioides brasiliensis, which is a highly pathogenic fungal species also endemic in Latin American countries [4]. The disease it causes, lacaziosis, is formerly known as Jorge Lobo's disease [5, 6] or lobomycosis until 2005 [7].

The characteristics of the disease are chronic keloidal skin lesions accompanied by pruritus, sensations of burning, and pain [2]. The hosts include humans and 3 species of dolphins: the bottlenose dolphin (Tursiops truncatus), the Indian Ocean bottlenose dolphin (Tursiops aduncus), and the estuarine dolphin, "costero" (Sotalia guianensis) [8]. Only one case of dolphin-to-human infection has been reported in a dolphin 


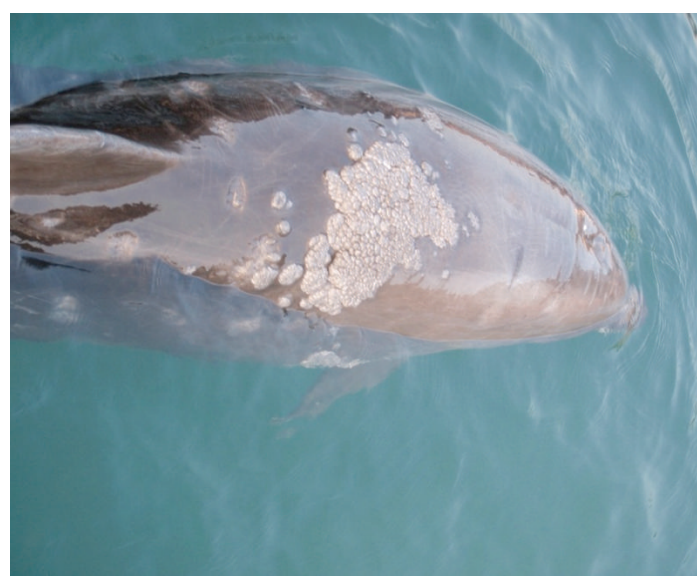

(a)

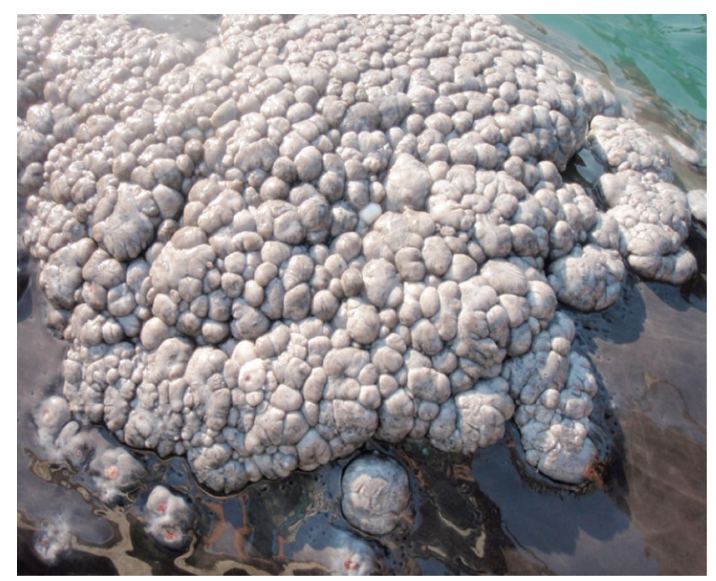

(b)

FIgURE 1: The skin lesion (approximately $25 \times 25 \mathrm{~cm}$ ) in Case 1 in August 2010 (a, b).

trainer in The Netherlands who contacted the infected animal, suggesting that lacaziosis should be considered a zoonotic fungal infection $[9,10]$.

Lacaziosis is usually found at altitudes above $200 \mathrm{~m}$ in tropical, humid, or subtropical forests with an average temperature of $24^{\circ} \mathrm{C}$ and more than $2,000 \mathrm{~mm}$ of annual rainfall $[1-3,8]$. The natural reservoir of $L$. loboi is unknown; however, its habitat is likely to be in rural environments on the basis of the observed distribution of the disease, and soil and vegetation seem to be probable sources of infection. Lacaziosis in dolphins suggests that some aquatic reservoir also exists $[2,3]$.

Human cases have been reported in Brazil, Costa Rica, Panama, Venezuela, Colombia, Guiana, Surinam, French Guiana, Ecuador, Peru, Bolivia, Honduras, and Mexico. Some cases have also been reported in the United States, but those patients thought to have been infected in Venezuela, Canada, The Netherlands, Surinam, France, South Africa [1$3,8,10]$, and Greece [11] bordering countries to the Atlantic Ocean. Interestingly, an unconfirmed case was reported from Bangladesh [12] which is not an endemic area.

On the other hand, cetacean cases have been reported in Brazil [13], Surinam [14], Florida and North Carolina (United States) [15-18], Mexico [19], the Bay of Biscay (Spain) [9], Spain in a dolphin that originated in Cuba [20], and Hawaii in a bottlenose dolphin transported from Florida [21]. Furthermore, lacaziosis-like cases have been observed in IndoPacific bottlenose dolphins in Mayotte waters located close to Madagascar, in the Indian Ocean [22], Venezuela, Colombia, Ecuador, Peru, Chile, Brazil [23], and in the Goto islands, Nagasaki Prefecture at the Kyushu area of the Japanese Sea [24]. Therefore, lacaziosis and lacaziosis-like diseases are endemic in the Atlantic, Pacific, and Indian Oceans [23]. According to Kiszka et al. [22], this lacaziosis-like disease is very similar to lobomycosis but lacks a histologic diagnosis [24]. Except for one case from Spain, most cases were diagnosed by photography and macroscopy without histopathologic, serologic, or molecular biological data [20].
The causative fungal species $L$. loboi, is difficult to culture except by animal passages $[2,3,8,10]$. Therefore, the diagnosis of lacaziosis is based on clinical symptoms, histopathologic observations, and immunologic tests by cross-reaction to Paracoccidioides brasiliensis, a closely related fungal species of Onygenales [1-4, 7, 8, 10]. Furthermore, the diagnosis seems to be very difficult confirm outside of endemic areas, where no doctor or veterinarian would consider lacaziosis when they encountered chronic granulomatous keloidal skin lesions either in humans or dolphins.

The present study aims to establish a diagnosis in two cases of lacaziosis in bottlenose dolphins captured simultaneously on the same coast of Japan and cared for in individual aquariums, on the basis of clinical characteristics, cytology, histopathology, immunological testing, and detection of partial sequences of the $43 \mathrm{kDa}$ glycoprotein coding gene ( $g p 43$ ) corresponding to those of $P$. brasiliensis $[4,7]$.

\section{Cases}

2.1. Case 1. A male bottlenose dolphin (Tursiops truncatus), estimated to be 17 years old, was captured in 2007 in a coastal area of Japan and cared for under outdoor conditions at an aquarium. The body weight and body length at the time of death were $280 \mathrm{~kg}$ and $303 \mathrm{~cm}$, respectively.

The dolphin's testosterone level decreased to less than $1 \mathrm{ng} / \mathrm{mL}$ beginning in March 2010. The skin of the back of the dolphin became swollen in July 2010. In August 2010, the skin developed a cauliflower-like eczema approximately $20 \times 25 \mathrm{~cm}$ in size (Figures $1(\mathrm{a})$ and $1(\mathrm{~b})$ ). The animal received antibiotics without effect. The blood $\beta$-glucan level was $22.4 \mathrm{pg} / \mathrm{mL}$ (>6 pg/mL is regarded as positive for fungal infection according to a commercial laboratory). The biopsied skin lesions contained yeast-like structures, as determined by a commercial pathology laboratory. The dolphin's condition was diagnosed as fungal infection, and terbinafine hydrochloride was administrated orally at a dose of $2 \mathrm{mg} / \mathrm{kg}$ SID. However, no improvement was noted. 


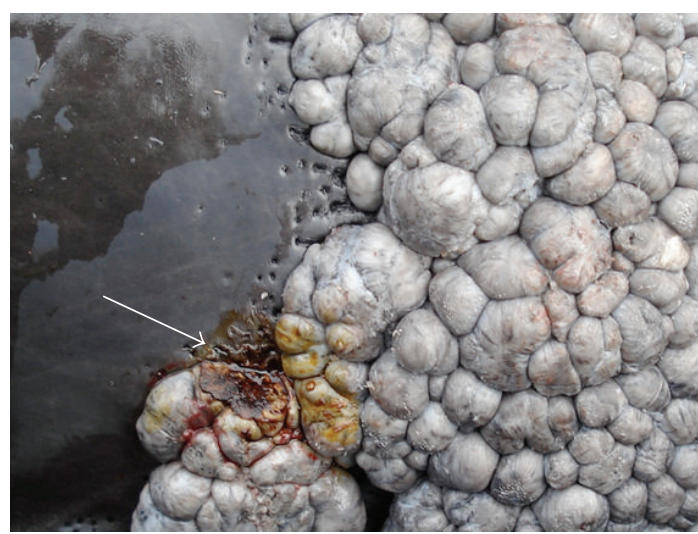

FIgURE 2: The margin of the skin lesion with abundant small fistulae appeared in November 2010. The arrow indicates the biopsy site.

In October 2010, the lesion had expanded, and pain was detected by palpation. Administration of fluconazole orally at a dose of $800 \mathrm{mg}(2.7 \mathrm{mg} / \mathrm{kg})$ was initiated; however, no effect was seen. The animal's body temperature was elevated slightly at $37^{\circ} \mathrm{C}$ or more. According to Hampton et al., the deep body temperature normally ranges from $37^{\circ} \mathrm{C}$ to $37.5^{\circ} \mathrm{C}$ during the active time; however, temperatures decrease during sleeping and after feeding times [25].

In November 2010, the body temperature decreased $\left(35^{\circ} \mathrm{C}\right)$, and the number of blood white cells increased to 33,000 cells $/ \mu \mathrm{L}$, while the normal number varies from 5,000 to $9,000 / \mu \mathrm{L}$ in captive dolphins [26]. The size of the lesion was approximately $30 \times 35 \mathrm{~cm}$. There were abundant small fistulae at the margin of the lesion (Figure 2). The biopsy was also done. The lesion had a topical temperature of approximately $40^{\circ} \mathrm{C}$, as detected by thermography (Figure 3(a)). The echo image of the lesion suggested that the invasion was limited to the subcutaneous connective tissue and did not extend to the muscle (Figure 3(b)). Round or multiple budding yeast cells consisting of a spherical to piriform mother cell $(4 \sim 12 \mu \mathrm{m}$ in diameter) with some small daughter cells (less than $0.5 \sim$ $6 \mu \mathrm{m} \mathrm{mm}$ in diameter) connected by a narrow base (less than $0.5 \mu \mathrm{m}$ in width and $0.5 \mu \mathrm{m}$ in length) were detected in the smear of the biopsied skin samples of the dermis stained with Giemsa, periodic acid-Schiff reaction (PAS), and Gomori methenamine method (GMS) (Figures 4(a)-4(c)).

On 19 December 2010, the animal showed a spontaneous increased respiratory ratio indicating lower vital signs. We speculated that the dolphin was suffering from sepsis and tried to administrate fluid replacement; however, there was no response. By the next day, the animal had died.

Purulent pneumonia and hepatic failure were detected at the autopsy. Staphylococcus aureus and Morganella morganii were isolated both from the lung and the blood. We concluded that the cause of the death was sepsis. In addition, the autopsied skin samples cultured on potato dextrose agar (Difco potato dextrose agar, Becton, Dickinson and Company Japan, Tokyo, Japan) supplemented with $100 \mathrm{mg} / \mathrm{L}$ of chloramphenicol and Mycosel agar (BBL Mycosel agar, Becton, Dickinson and Company Japan) plates at 25 and $35^{\circ} \mathrm{C}$ for 4 weeks produced negative results.
Abundant yeast-like cells were detected in the skin lesions stained with hematoxylin and eosin, PAS, and GMS (Figures $5(\mathrm{a})-5(\mathrm{c}))$. Most of the yeast cells appeared as chains, while multiple budding yeast cells connected by narrow bases to the mother cells were also detected.

For immunohistochemistry, sections from skin lesions were incubated with a rabbit polyclonal antibody against $P$. brasiliensis which is a related species to $L$. loboi for $16 \mathrm{hrs}$ at $4^{\circ} \mathrm{C}$. The bounded antibodies were detected with horse radish peroxidase conjugated to anti-rabbit secondary antibody (Histofine Simple Stain MAXPO; Nichirei, Tokyo, Japan) and 3,3'-diaminobenzidine tetrahydrochloride (DAB, Vector Laboratories Inc., Burlingame, CA, USA) as chromogen. The yeast cells reacted positively to immune-staining by anti-P. brasiliensis rabbit serum (Figure 5(d)).

The serum obtained at death showed a slight precipitation line in the immunodiffusion test against a fungal cell antigen of $P$. brasiliensis detected by macroscopical observation on a slit lighting system.

Detection of the $43 \mathrm{kDa}$ glycoprotein coding gene ( $g p 43$ ) with reference to the sequences of $P$. brasiliensis, $P$. lutzii, and L. lobo $i$ was tried because of adequate sequence data in the GenBank database and its high homology [7].

The biopsied or paraffin-embedded specimens were examined. The fresh samples were fixed with $70 \%$ ethanol at least overnight, cut into approximately $5 \times 5 \times 5 \mathrm{~cm}^{3}$ sized pieces, and placed into a $1.5 \mathrm{~mL}$ sized sterile microtube. The samples were washed 3 times with sterile water by centrifugation at 13,201 $\mathrm{g}$ for $5 \mathrm{~min}, 0.5 \mathrm{~mL}$ of DEXPAT (TaKaRa, Otsu, Japan) solution for DNA elution was added, and they were heated at $100^{\circ} \mathrm{C}$ for $10 \mathrm{~min}$. Then the microtubes containing the tissue samples and DNA eluting solution were cooled on ice and centrifuged at 13,201 $\mathrm{g}$ for $10 \mathrm{~min}$. The supernatant was collected and stored as a crude DNA solution. For paraffinembedded tissue samples, 3 sections of $10 \mu \mathrm{m}$ thick paraffinembedded tissues were placed into micro tubes $(1.5 \mathrm{~mL})$, and $0.5 \mathrm{~mL}$ of DEXPAT solution was added. After being boiled for $10 \mathrm{~min}$., the tubes were centrifuged at 13,201 $\mathrm{g}$ for $10 \mathrm{~min}$, and the supernatants were stored as crude DNA solutions. After being purified by an ethanol precipitation method, the DNA solutions were processed to amplify $g p 43$ using a primer set for $g p 43$ of $P$. brasiliensis [27]. It is because that both $P$. brasiliensis and L. loboi are closely related fungal species [7] and showed higher homology in the gene sequences [4].

We placed $2.5 \mu \mathrm{L}$ of the sample, $2.5 \mu \mathrm{L}$ of $20 \mathrm{pM}$ primers $\operatorname{MAE}\left(5^{\prime}-\right.$ TGCTGCGGCGGGGTTAAACCATGTC- $\left.3^{\prime}\right)$ and ATO (5'-GTTGTGGTATGTGTCGATGTAGACG-3') [27], and $17.5 \mu \mathrm{L}$ of distilled water in a $0.2 \mathrm{~mL}$ PCR tube with one Ready-to-Go bead (Amersham Pharmacia, Tokyo, Japan). The reaction mixture was subjected to 1 cycle of denaturation at $95^{\circ} \mathrm{C}$ for $4 \mathrm{~min}, 40$ cycles of amplification at $94^{\circ} \mathrm{C}$ for $1 \mathrm{~min}$, $50^{\circ} \mathrm{C}$ for $1.5 \mathrm{~min}, 72^{\circ} \mathrm{C}$ for $2 \mathrm{~min}$, and then a final extension step at $72^{\circ} \mathrm{C}$ for $10 \mathrm{~min}$ in a PCR Thermal Cycler MP (TaKaRa, Otsu, Japan). For amplification in the second-round PCR, the first PCR product was processed by the ethanol precipitation method, and the same PCR reaction was repeated.

The PCR products were approximately 550-base pair sized bands amplified from both fresh and paraffin-embedded tissue samples. The sequences were determined by 


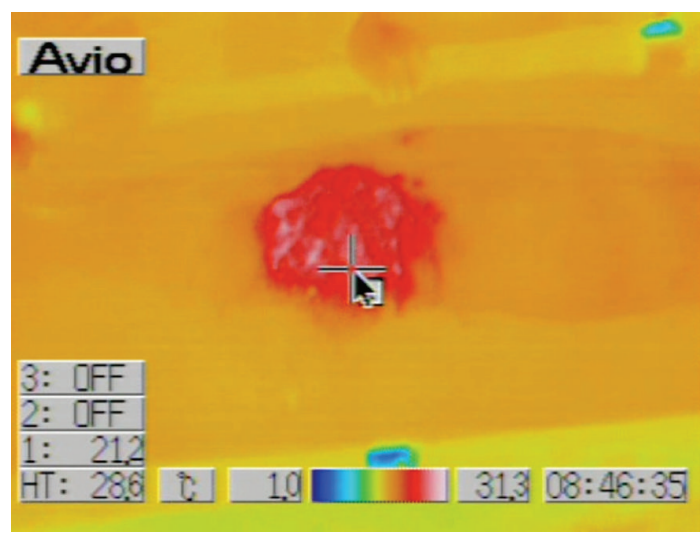

(a)

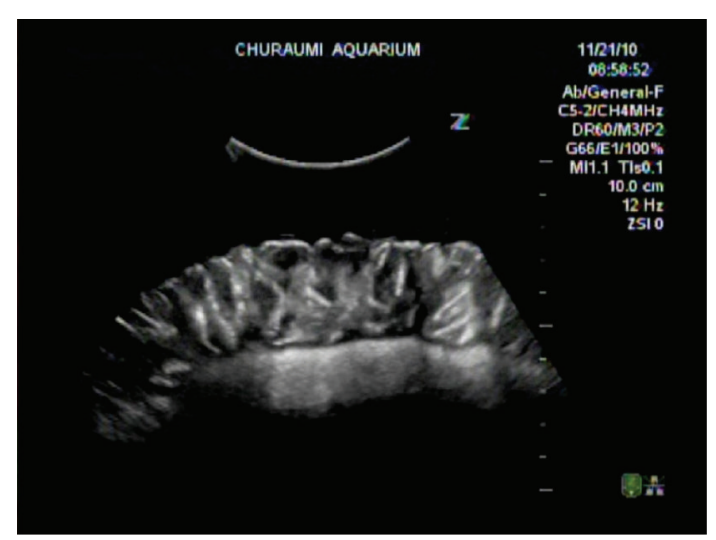

(b)

Figure 3: A topical temperature of approximately $40^{\circ} \mathrm{C}$ (arrow) was determined by a thermographic image of the lesion (a), and the depth of invasion was detected by an echo system (b).

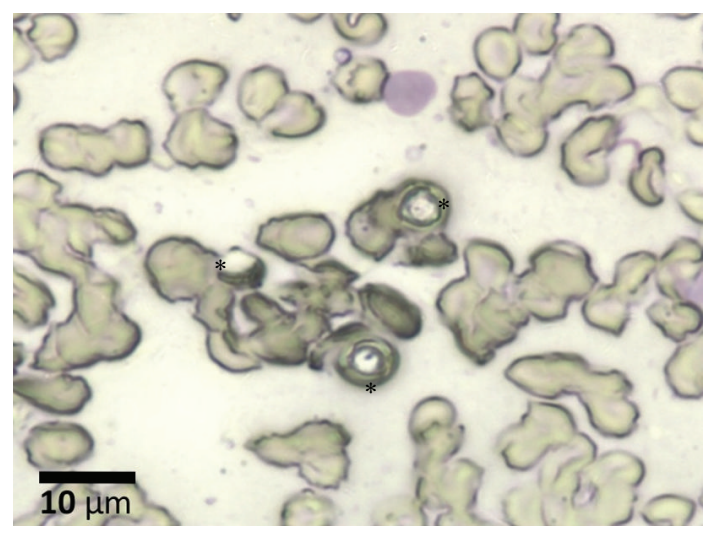

(a)

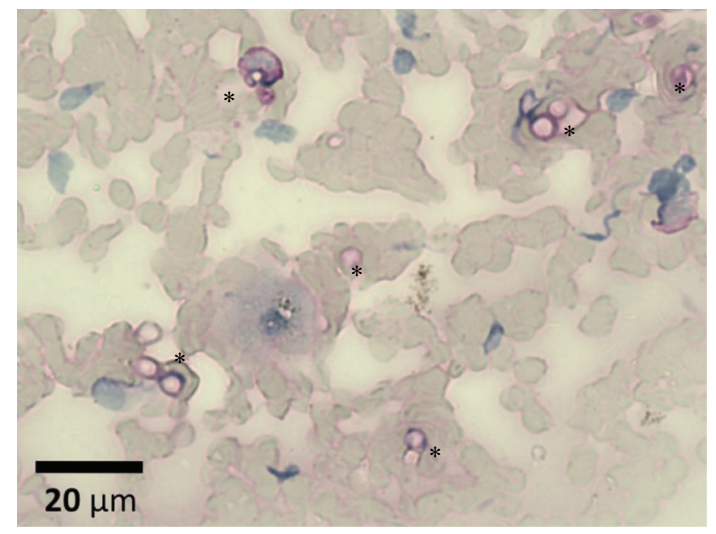

(b)

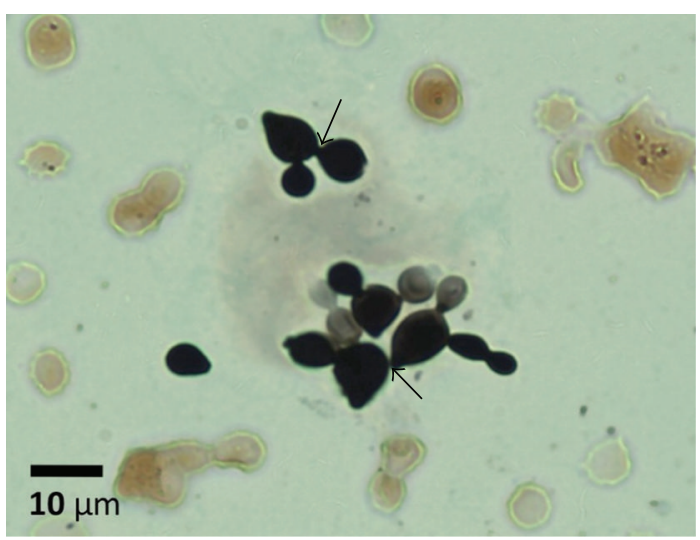

(c)

Figure 4: Spherical yeast cells $(*)$ stained with Giemsa $(\times 200$, (a)), with PAS $(\times 200,(b))$, and spherical to piriform mother cells with some small daughter cells connected by a narrow base (arrows) stained with GMS $(\times 400,(\mathrm{c}))$.

a direct sequencing method using ABI PRISM 3100 sequencer (Applied Biosystems) labeled with the primers MAE and ATO [28]. DNA sequences were aligned with the GENETEXMAC genetic information processing software (Software Development Co., Ltd., Tokyo, Japan). The reliable sequence comprised 471 bases obtained from the paraffin-embedded tissue sample; however, the biopsied sample failed to confirm the sequence. The accession numbers of this sequence were registered as AB811031 in the GenBank database. The sequence was localized in the cluster containing P. brasiliensis, 


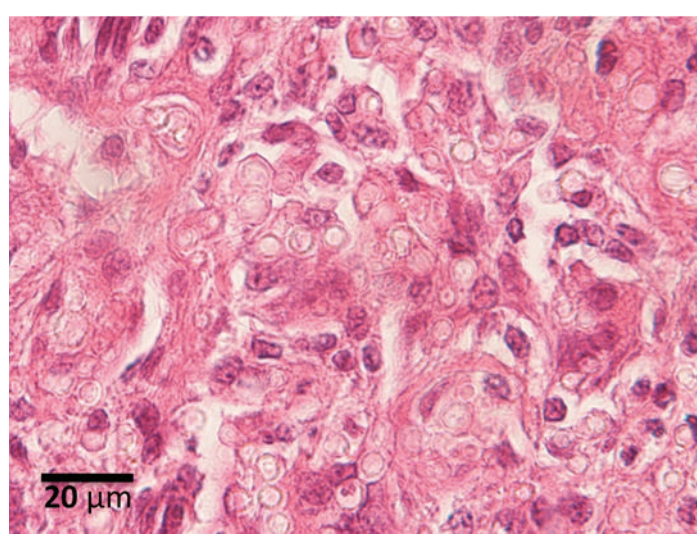

(a)

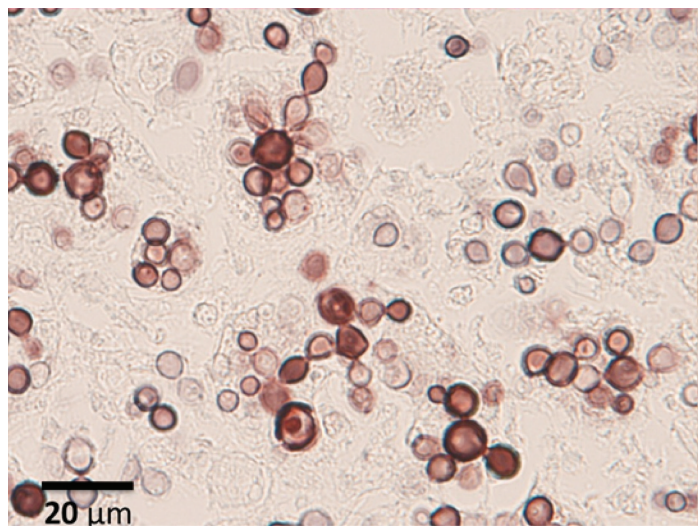

(c)

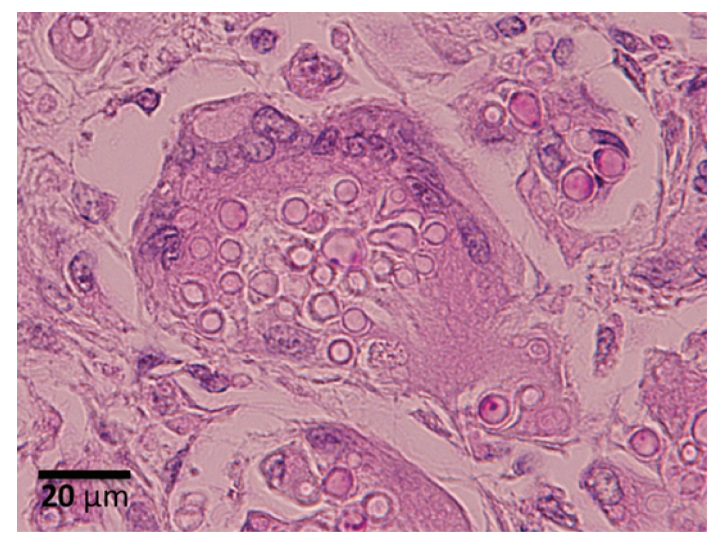

(b)

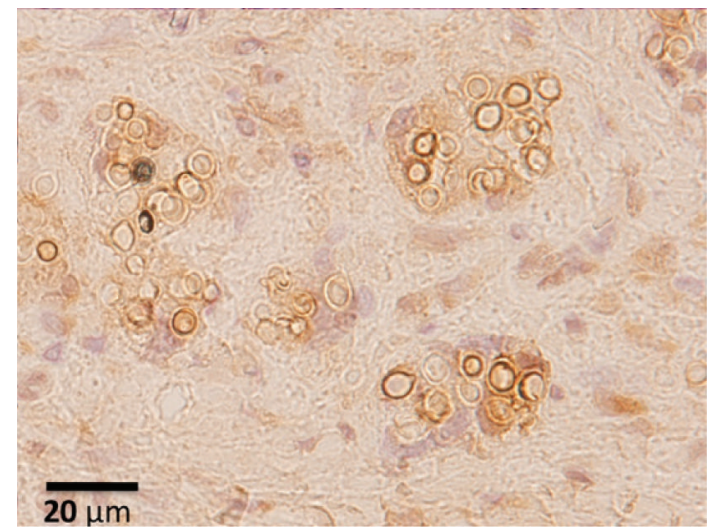

(d)

FIGURE 5: Yeast-like cells appeared as abundant round hyaline cells stained with hematoxylin and eosin $(\times 200$, (a)), PAS positive cells arranged in a multiple budding detected in a giant cell stained with PAS $(\times 200,(b))$, well-defined chains or multiple buddings stained with GMS $(\times 200$, (c)), and positive in immune-staining with anti-P. brasiliensis rabbit serum $(\times 200,(\mathrm{~d}))$ in the dermis.

P. lutzii, and L. loboi through a BLAST search (http://blast .ncbi.nlm.nih.gov/).

The 471 base pairs sequence showed $94.9 \%$ homology to $P$. brasiliensis (PBU26160) [29], 87.7\% to P. lutzii (XM00279244), and $84.1 \%$ to L. loboi (EU109947) [4] (Table 1). The homologies to fungal species related to Paracoccidioides spp., such as Ajellomyces dermatitidis (XM_002624715) and A. capsulatus (XM_001540694) retrieved from the GenBank database (http://www.ncbi.nlm.nih.gov/genbank/), were 66.3 and $63.6 \%$, respectively (Table 1 ).

We diagnosed the dolphin as lacaziosis on the basis of the clinical characteristics of the skin lesion, cytologic and histopathologic findings, immunostaining and immunodiffusion test, and the molecular biological study.

2.2. Case 2. A female bottlenose dolphin (Tursiops truncatus), estimated to be 5 years of age, was captured in 2007 in the coastal region of Japan simultaneously with the Case 1 dolphin and cared for under outdoor conditions in an aquarium at the same institution as Case 1 for 2 years. Then the animal was transported to the present aquarium where it was cared for until its death. The body weight and body length at the time of death were $175 \mathrm{~kg}$ and $240 \mathrm{~cm}$.
The dolphin had two granulomatous lesions in the skin of both upper eye lids in February 2011 (Figures 6(a) and 6(b)). The lesions expanded by March 2011. We hypothesized that the animal might suffer from lacaziosis and performed a biopsy. There were some yeast-like components on the smears of the lesions stained by Giemsa solution (data not shown); however, yeast cells were not detected by histopathology, and gp43 was not amplified. In addition, Candida glabrata was detected from the breath.

In May 2011, we biopsied and cauterized the lesions. $C$. glabrata and Aspergillus niger were detected on the breath. The animal received topical applications of ketoconazole cream and oral administration of itraconazole $1,000 \mathrm{mg} /$ body BID followed by antibiotics and hydrocortisone. In addition, a granulomatous mass at the oral cavity appeared (Figure 7(a)).

We started to measure the blood $\beta$-glucan levels in June 2011 and found $8-41 \mathrm{pg} / \mathrm{mL}$ during July and August 2011, which indicated a fungal infection.

In September 2011, a new skin lesion appeared on the back fin (data not shown). Several scars caused by shark bites also became granulomatous (Figure 7(b)). We biopsied these lesions and detected multiple budding yeast-like cells 
TABLE 1: Homologies of the partial sequence of gp43 to Paracoccidioides brasiliensis, P. lutzii, Lacazia loboi, Ajellomyces dermatitidis, and A. capsulatus.

\begin{tabular}{|c|c|c|c|c|}
\hline GenBank accession no. & bps & Position (total bases) & Identity (\%) & Isolate or ID [ref] \\
\hline Present case & 471 & $1-471(471)$ & - & SUM \\
\hline \multicolumn{5}{|c|}{ Paracoccidioides brasiliensis } \\
\hline PBU26160 & 466 & 2603-3068 (3702) & 94.9 & B339 [29] \\
\hline \multicolumn{5}{|l|}{ P. lutzii } \\
\hline XM_002792442* & 466 & $1136-1601(2016)$ & 87.7 & $\mathrm{~Pb} 01$ \\
\hline \multicolumn{5}{|l|}{ Lacazia loboi } \\
\hline EU109947 & 463 & $1-463(483)$ & 84.1 & 10-RMS [4] \\
\hline \multicolumn{5}{|l|}{ Ajellomyces dermatitidis } \\
\hline XM_002624715* & 469 & $484-952(1260)$ & 66.5 & SLH14081 \\
\hline \multicolumn{5}{|l|}{ A. capsulatus } \\
\hline XM_001540694* & 469 & $475-943(1251)$ & 63.3 & Naml \\
\hline
\end{tabular}

* The sequence was retrieved from the GenBank database.

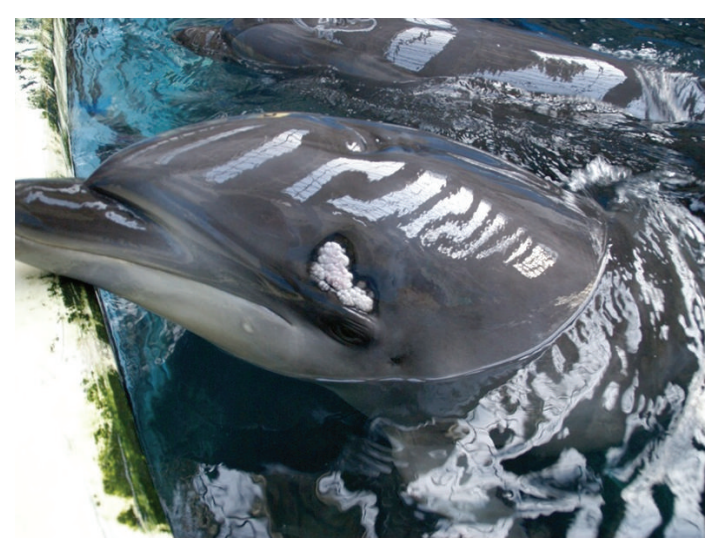

(a)

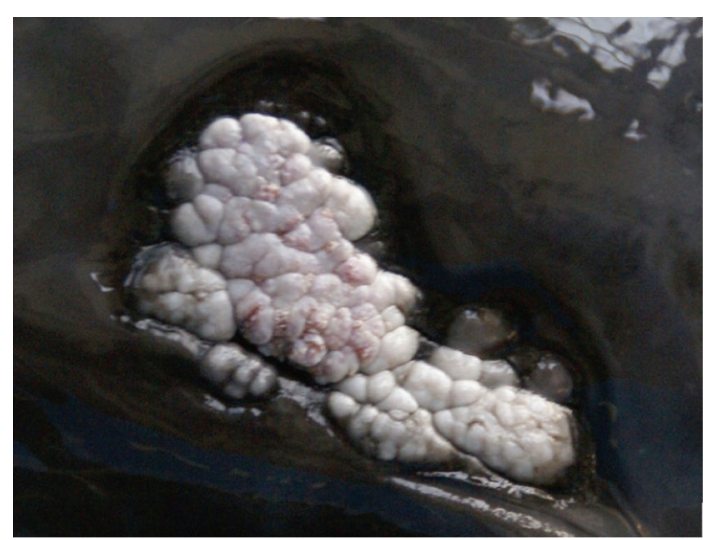

(b)

Figure 6: Granulomatous skin lesions of Case 2 at the left upper eye-lid in February 2011 (a, b).

by cytologic observation of samples stained by Giemsa (Figure 8(a)), mounted with 5\% $\mathrm{KOH}$ (Figure 8(c)), and added with lactophenol cotton blue (Figure 8(c)) and GMS (Figure $8(\mathrm{~d})$ ). All biopsied skin samples from May, June, and September 2011 cultured on potato dextrose agar supplemented with $100 \mathrm{mg} / \mathrm{L}$ of chloramphenicol and Mycosel agar plates at 25 and $35^{\circ} \mathrm{C}$ for 4 weeks were negative.

The DNAs derived from Case 2 were not amplified through the PCR conditions used in Case 1. Therefore, we designed an inner primer set: SUM F1 (5'-GTCATCGATCTCCATGGTGTTAAG-3') and SUM R2 (5'-GGCAGARAAGCATCCGAAA- $\left.3^{\prime}\right)$ with reference to the $g p 43$ sequences from $P$. brasiliensis (PBU26160, AY005408, and AB304681) and L. loboi (AY697436 and EU109947); the sequence determined in the Case 1-derived DNA was aligned by GENETYX-MAC ver. 12.0 genetic information processing software (GENETYX CORPORATION, Tokyo, Japan). The PCR condition was as the same as the first PCR.

We detected 382 base pairs of a partial sequence of $g p 43$ showing $100 \%$ identity to those from Case 1 by the nestedPCR system from the biopsied sample collected at the above times.
The serum also showed a slight precipitation line in the immunodiffusion test against a fungal cell antigen of $P$. brasiliensis (data not shown).

On the basis of these clinical characteristics and cytologic and molecular biological observations, we made a diagnosis of lacaziosis.

The dolphin died suddenly in December 2012. The animal had shown a higher respiratory ratio at 7 times per min since the summer of 2012. The macroscopic findings were intestinal occlusion caused by cardiac disorder, pulmonary chronic inflammation, and one purulent cyst at the scar from cauterization of the animal's lesion without yeast-like cells.

\section{Discussion}

The present 2 dolphins showing chronic granulomatous skin lesions represent the first examples of lacaziosis from Pacific Ocean diagnosed on the basis of clinical, cytologic, histologic, serologic, and molecular biological data. Although many cases of lacaziosis-like diseases in dolphins from Ecuador, Colombia, Peru, and Chile along the coast of the Pacific Ocean have been recorded, they were diagnosed by 


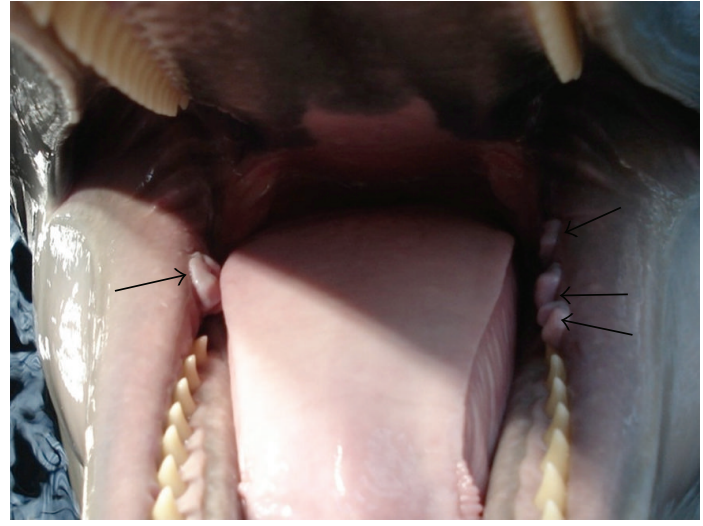

(a)

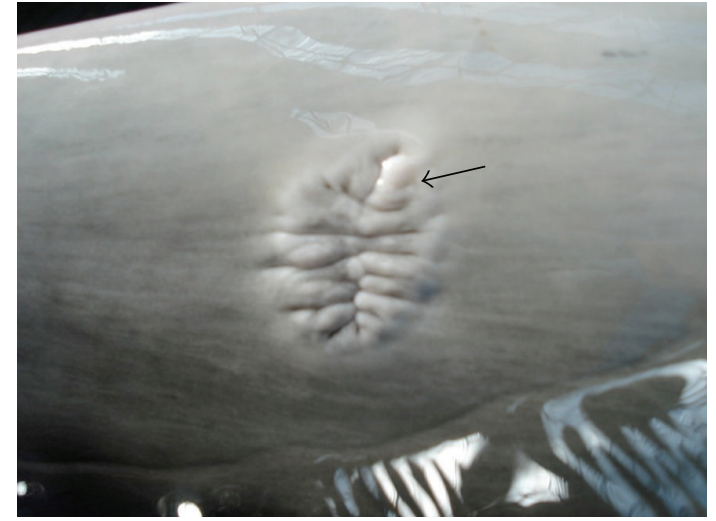

(b)

FIGURE 7: Granulomatous masses at the oral cavity appeared in May 2011 (arrows, (a)). One of the newly appeared skin lesions on the scars caused by a shark bite in September 2011 (arrow, (b)).

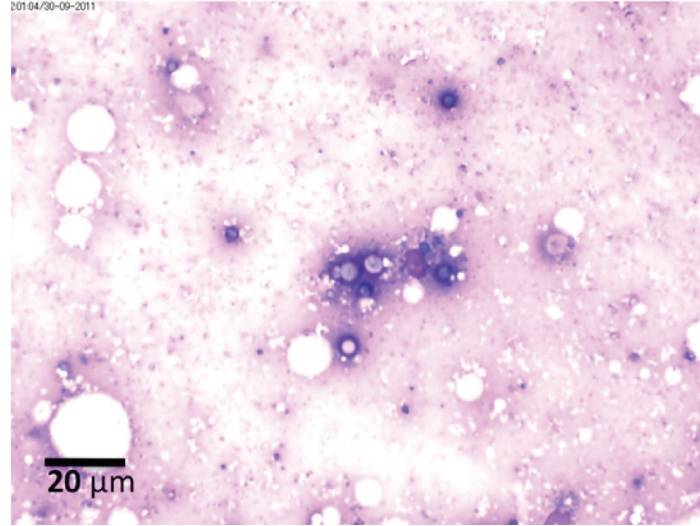

(a)

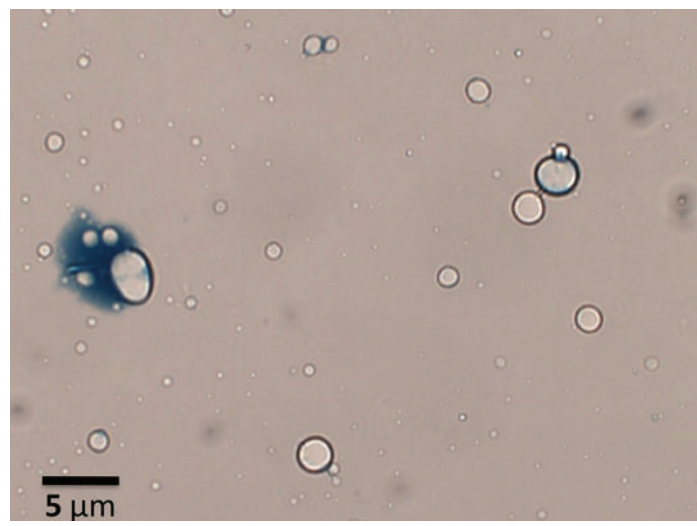

(c)

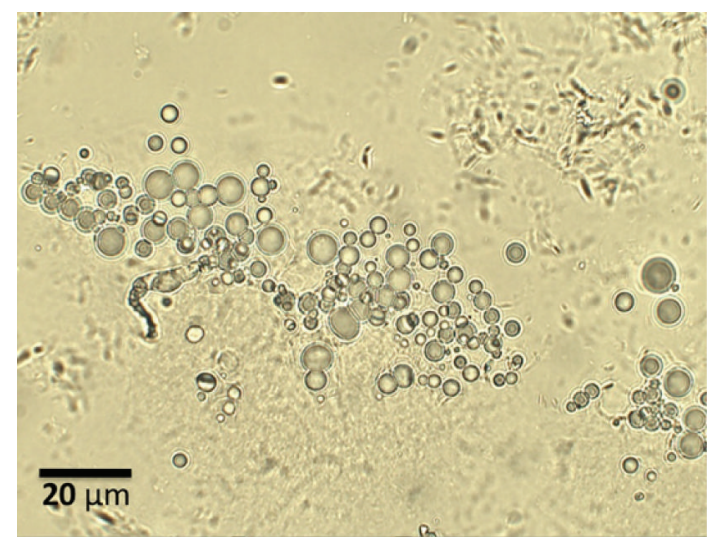

(b)

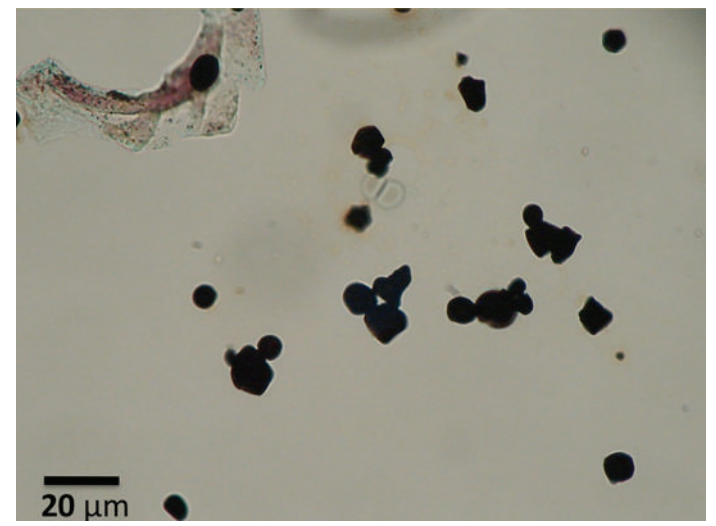

(d)

FIGURE 8: Multiple budding yeast-like cells derived from Case 2 stained by Giemsa $(\times 200$, (a)), in $5 \% \mathrm{KOH}$ mount $(\times 200$, (b)), in $5 \% \mathrm{KOH}$ plus lactophenol cotton blue $(\times 400,(c))$, and stained with GMS $(\times 200,(d))$.

macroscopy and photography without histopathologic and molecular biological data [23]. Furthermore, some lacaziosislike diseases have been recorded in dolphins in Japanese waters [24]; however, those cases were also diagnosed by photographic images. Therefore, the present cases are the first of lacaziosis from the Pacific Ocean to be diagnosed according to the definition recommended by Kiszka et al. [22] as follows: lacaziosis-like disease is very similar to lobomycosis but lacking a histologic diagnosis.

The serum cross-reaction in the immunodiffusion test with $P$. brasiliensis antigen and positive immune-staining with $P$. brasiliensis antisera have previously been reported as 
characteristics of lacaziosis [30]. The slightly positive reaction in the immunodiffusion test with $P$. brasiliensis antigen and the positive results upon immune-staining were matched to Brazilian human lacaziosis.

Establishing a diagnosis of lacaziosis requires clinical data, cytologic observation, histopathologic techniques, immunological methods, and detection of species-specific genes because of the difficultly of culture $[2,3,8,10]$. Furthermore, it seems very unlikely that cutaneous lesions of cauliflower-like eczema in dolphins would be recognized as lacaziosis outside of endemic areas. In such cases, molecular biological techniques are useful.

In general, identification of fungal species is made on the basis of the internal transcribed spacer (ITS)-1-5.8S-ITS-2 regions of ribosomal RNA (ITS rRNA) gene sequences with more than 98 to $99 \%$ diversity between species or at least $95 \%$ even in a fungal species with higher intraspecies diversity [31]. However, we failed to detect the ITS rRNA gene from the dolphins' samples in the present study and could not compare to those from the Atlantic Ocean [20].

Interestingly, Esperón et al. reported that the ITS region of the ribosomal RNA sequence derived from dolphins living in the Atlantic Ocean was more related to P. brasiliensis than to L. loboi [20]. The preset cases also showed a close relationship of the genotype of the $g p 43$ to $P$. brasiliensis. Further study may confirm that the genotypes of lacaziosis out of Amazon areas.

The virulence of lacaziosis endemic in Japanese waters remains unknown; however, the disease seems to be virulent among dolphins since the animals that have spent a period in the same tribe suffered lacaziosis caused by identical genotype. They might be infected by contact or receive the pathogen simultaneously, and/or endemic in the tribe.

Lacaziosis sometimes causes immune disorders in dolphins [32]. Although we could not evaluate immune markers, the present animals suffered fatal outcomes caused by systemic bacterial infections or cardiac and respiratory problems, indicating that they were suffering from severe immune disorders.

Japan is a maritime nation. Many people in Japan have contact with the sea and marine products: not only fishermen but also the general public through swimming, fishing, boating, and visiting the marine aquarium. Therefore, we speculate that some latent human cases of lacaziosis may exist in our country.

\section{Conclusions}

We diagnosed 2 cases of lacaziosis in bottlenose dolphins on the basis of clinical, cytologic, histologic, serologic, and molecular biological data and confirmed that the causative agent at the present cases was a different genotype of L. loboi from Amazon area.

\section{Conflict of Interests}

The corresponding author, Ayako Sano, declared that there is no conflict of interests submitted to the University of the Ryukyus no. H24-763.

\section{Acknowledgments}

This study was supported in part by the Special Research Fund for Emerging and Re-emerging Infections of the Ministry of Health, Welfare and Labor (Grant no. H-21-Shinkou004). The authors express their thanks to Ms. Michiko Murata (Azabu University) for technical support on the preliminary sequencing of $g p 43$.

\section{References}

[1] P. R. Taborda, V. A. Taborda, and M. R. McGinnis, "Lacazia loboi gen. nov., comb. nov., the etiologic agent of lobomycosis," Journal of Clinical Microbiology, vol. 37, no. 6, pp. 2031-2033, 1999.

[2] M. Ramos-E-Silva, F. Aguiar-Santos-Vilela, A. Cardoso-DeBrito, and S. Coelho-Carneiro, "Lobomycosis. Literature review and future perspectives," Actas Dermo-Sifiliograficas, vol. 100, no. 1, pp. 92-100, 2009.

[3] S. Talhari and C. Talhari, "Lobomycosis," Clinics in Dermatology, vol. 30, no. 4, pp. 420-424, 2012.

[4] R. Vilela, P. S. Rosa, A. F. F. Belone, J. W. Taylor, S. M. Diório, and L. Mendoza, "Molecular phylogeny of animal pathogen Lacazia loboi inferred from rDNA and DNA coding sequences," Mycological Research, vol. 113, no. 8, pp. 851-857, 2009.

[5] A. Fialho, "Blastomicose du tipo, "JorgeLobo"', O Hospital, (Rio De Janeiro), vol. 14, article 903, 1938.

[6] D. Borelli, “Aspergillus, sorpresas en micopatologia," Dermatologia Venezolana, vol. 1, article 286, 1958.

[7] R. Vilela, L. Mendoza, P. S. Rosa et al., "Molecular model for studying the uncultivated fungal pathogen Lacazia loboi," Journal of Clinical Microbiology, vol. 43, no. 8, pp. 3657-3661, 2005.

[8] K. L. Horner and G. J. Raugi, “Lobomycosis on MedScape," 2012, http://emedicine.medscape.com/article/1092451-overview.

[9] W. C. Symmers, "A possible case of Lobo's disease acquired in Europe from a bottle-nosed dolphin (Tursiops truncatus)," Bulletin de la Societe de Pathologie Exotique et de ses Filiales, vol. 76, no. 5, pp. 777-784, 1983.

[10] A. Paniz-Mondolfi, C. Talhari, L. Sander Hoffmann et al., "Lobomycosis: an emerging disease in humans and delphinidae," Mycoses, vol. 55, no. 4, pp. 298-309, 2012.

[11] E. Papadavid, M. Dalamaga, I. Kapniari et al., "Lobomycosis: a case from Southeastern Europe and review of the literature," Journal of Dermatological Case Reports, vol. 6, no. 3, pp. 65-69, 2012.

[12] T. K. Rumi and R. A. Kapkaev, "Keloidal blastomycosis (Lobo's disease)," Vestnik Dermatologii $i$ Venerologii, no. 11, pp. 41-43, 1988.

[13] P. C. Simões-Lopes, G. S. Paula, F. M. Xavier, and A. C. Scaramelo, "First case of lobomycosis in bottlenose dolphin from southern Brazil," Marine Mammal Sciences, vol. 9, no. 3, pp. 329331, 1993.

[14] G. A. De Vries and J. J. Laarman, "A case of Lobo's disease in the dolphin Sotalia guianensis," Aquatic Mammals, vol. 1, pp. 1-8, 1973.

[15] G. Migaki, M. G. Valerio, B. Irvine, and F. M. Garner, "Lobo's disease in an atlantic bottle-nosed dolphin," Journal of the American Veterinary Medical Association, vol. 159, no. 5, pp. 578-582, 1971. 
[16] D. K. Caldwell, M. C. Caldwell, and J. C. Woodard, "Lobomycosis as a disease of the Atlantic bottlenosed dolphin (Tursiops truncatus Montagu, 1821)," American Journal of Tropical Medicine and Hygiene, vol. 24, no. 1, pp. 105-114, 1975.

[17] J. S. Reif, M. S. Mazzoil, S. D. McCulloch et al., "Lobomycosis in Atlantic bottlenose dolphins from the Indian River Lagoon, Florida," Journal of the American Veterinary Medical Association, vol. 228, no. 1, pp. 104-108, 2006.

[18] D. S. Rotstein, L. G. Burdett, W. McLellan et al., "Lobomycosis in offshore bottlenose dolphins (Tursiops truncatus), North Carolina," Emerging Infectious Diseases, vol. 15, no. 4, pp. 588590, 2009.

[19] D. F. Cowan, "Lobo's disease in a bottlenose dolphin (Tursiops truncatus) from Matagorda Bay, Texas," Journal of Wildlife Diseases, vol. 29, no. 3, pp. 488-489, 1993.

[20] F. Esperón, D. García-Párraga, E. N. Bellière, and J. M. SánchezVizcaíno, "Molecular diagnosis of lobomycosis-like disease in a bottlenose dolphin in captivity," Medical Mycology, vol. 50, no. 1, pp. 106-109, 2012.

[21] J. P. Schroeder, "Apparent toxicity of ketoconazole for Tursiaps truncatus during treatment of lobomycosis," in Proceedings of the IAAAM 14th Annual Conference and Workshop, Long Beach, Calif, USA, May 1983.

[22] J. Kiszka, M.-F. Van Bressem, and C. Pusineri, "Lobomycosislike disease and other skin conditions in Indo-Pacific bottlenose dolphins Tursiops aduncus from the Indian Ocean," Diseases of Aquatic Organisms, vol. 84, no. 2, pp. 151-157, 2009.

[23] B. Bedrinana-Romano, B. Best, C. Brownell et al., "Report of the workshop on cetacean skin diseases," The Journal of Cetacean Research and Management, vol. 11, supplement, pp. 503-514, 2009.

[24] M. F. Van Bressem, M. Shirakihara, and M. Amano, "Cutaneous nodular disease in a small population of Indo-Pacific bottlenose dolphins, Tursiops aduncus, from Japan," Marine Mammal Science, vol. 29, no. 3, pp. 525-532.

[25] I. F. G. Hampton, G. C. Whittow, J. Szekerczes, and S. Rutherford, "Heat transfer and body temperature in the atlantic bottlenose dolphin, Tursiops truncatus," International Journal of Biometeorology, vol. 15, no. 2-4, pp. 247-253, 1971.

[26] G. D. Bossart, T. H. Reidarson, L. A. Dierauf, and D. A. Duffield, "Clinical pathology," in CRC Handbook of Marine Mammal Medicine, L. A. Dierauf and F. M. D. Gulland, Eds., Chapter 19, pp. 383-436, CRC Press, Washington, DC, USA, 2nd edition, 2001.

[27] A. Sano, K. Yokoyama, M. Tamura et al., "Detection of $g p 43$ and ITS1-5.8S-ITS2 ribosomal RNA genes of Paracoccidioides brasiliensis in paraffin-embedded tissue," Nihon Ishinkin Gakkai Zasshi, vol. 42, no. 1, pp. 23-27, 2001.

[28] A. Takayama, E. N. Itano, A. Sano, M. A. Ono, and K. Kamei, "An atypical Paracoccidioides brasiliensis clinical isolate based on multiple gene analysis," Medical Mycology, vol. 48, no. 1, pp. 64-72, 2010.

[29] P. S. Cisalpino, R. Puccia, L. M. Yamauchi, M. I. N. Cano, J. F. Da Silveira, and L. R. Travassos, "Cloning, characterization, and epitope expression of the major diagnostic antigen of Paracoccidioides brasiliensis," Journal of Biological Chemistry, vol. 271, no. 8, pp. 4553-4560, 1996.

[30] Z. P. Camargo, R. G. Baruzzi, S. M. Maeda, and M. C. Floriano, "Antigenic relationship between Loboa loboi and Paracoccidioides brasiliensis as shown by serological method," Medical Mycology, vol. 36, no. 6, pp. 413-417, 1998.
[31] S. A. Balajee, A. M. Borman, M. E. Brandt et al., "Sequencebased identification of aspergillus, fusarium, and mucorales species in the clinical mycology laboratory: where are we and where should we go from here?" Journal of Clinical Microbiology, vol. 47, no. 4, pp. 877-884, 2009.

[32] J. S. Reif, M. M. Peden-Adams, T. A. Romano, C. D. Rice, P. A. Fair, and G. D. Bossart, "Immune dysfunction in Atlantic bottlenose dolphins (Tursiops truncatus) with lobomycosis," Medical Mycology, vol. 47, no. 2, pp. 125-135, 2009. 

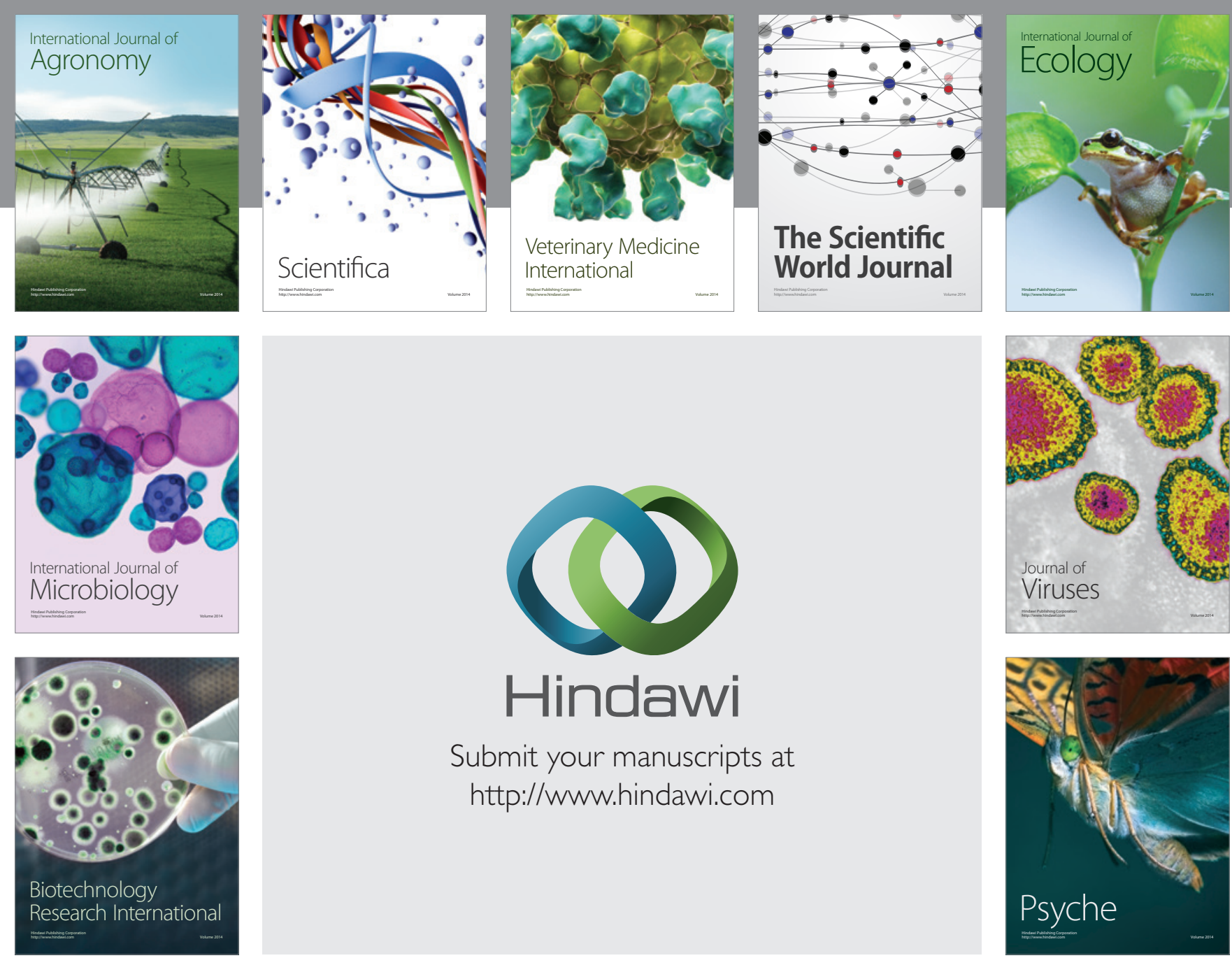

Submit your manuscripts at http://www.hindawi.com
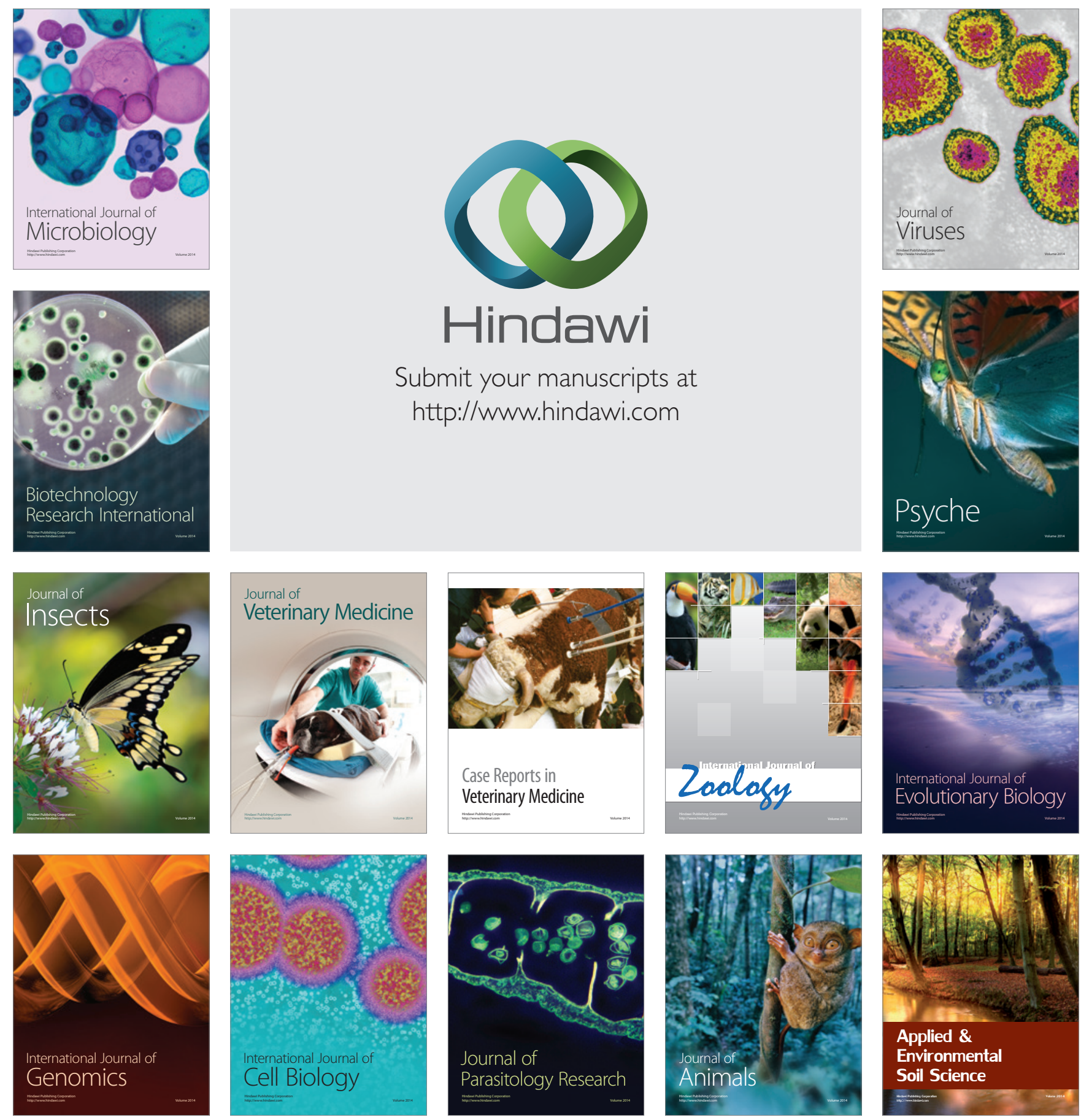